\title{
Interactions between anti-EGFR therapies and cytotoxic chemotherapy in oesophageal squamous cell carcinoma: Why clinical trials have failed and how they could succeed
}

\author{
Madusha Meemanage \\ University of Dundee School of Medicine \\ Lindsay C Spender \\ University of Dundee School of Medicine \\ Diane Collinson \\ University of Aberdeen \\ Joanna lannetta
}

University of Dundee School of Medicine

Pranavi Challapalli

University of Dundee School of Medicine

Julie Turbitt

University of Aberdeen

Caroline Clark

University of Aberdeen

Mark Baxter

University of Dundee School of Medicine

Graeme Murray

University of Aberdeen

Shaun Walsh

NHS Tayside

Zofia Miedzybrodzka

University of Aberdeen

Russell Petty ( $\nabla$ r.petty@dundee.ac.uk)

University of Dundee School of Medicine

\section{Research}

Keywords: Gastroesophageal cancer, gefitinib, EGFR, cytotoxic chemotherapy, ESCC, drug combination

Posted Date: May 28th, 2020 
DOI: https://doi.org/10.21203/rs.3.rs-31064/v1

License: (c) (i) This work is licensed under a Creative Commons Attribution 4.0 International License. Read Full License 


\section{Abstract \\ BACKGROUND}

Oesophageal squamous cell carcinoma (ESCC) has high mortality and poor prognosis. Advanced tumours are treated with fluoropyrimidine/platinum chemotherapy (PBC) followed by second-line irinotecan or taxane monotherapy, but resistance is common and new therapeutic approaches are needed. Approximately $20 \%$ of ESCC tumours carry copy number gain (CNG) of the epidermal growth factor receptor (EGFR) gene. Previous analysis of randomised clinical trials shows that anti-EGFR monotherapy benefits biomarker-selected patients with EGFR CNG and/or high expression by Immunohistochemistry (IHC). However, responses are often of short duration indicating that combining anti-EGFR therapy with other agents is required to optimise the benefit from anti-EGFR therapies even in biomarker selected patients. Randomised clinical trials have not shown benefit from the addition of antiEGFR therapies to platinum fluoropyrimidine chemotherapy and uncertainty remains regarding the optimal cytotoxic chemotherapy partner for anti-EGFR therapies in ESCC.

\section{METHODS}

The effects of EGFR CNG on sensitivity to PBC in a cohort of gastroesophageal cancer patients $(\mathrm{n}=302)$ was evaluated. Drug combination studies using the EGFR inhibitor gefitinib with cytotoxic chemotherapies, docetaxel, cisplatin, oxaliplatin and irinotecan, on cell proliferation and cell death of EGFR CNG ESCC cell lines were assessed.

\section{RESULTS}

EGFR CNG in gastroesophageal cancer patients was associated with better overall survival following platinum-based chemotherapy. Drug combination studies showed that co-administration of gefitinib and platinum-based cytotoxics was frequently antagonistic in cell-based assays in EGFR CNG ESCC, whereas the combination of gefitinib with docetaxel or irinotecan was more efficacious. Co-administration of gefitinib/docetaxel and sequential administration of docetaxel before gefitinib showed synergy, but docetaxel given after gefitinib was antagonistic.

\section{CONCLUSIONS}

Gefitinib/docetaxel co-administration demonstrated synergy and taxanes are likely to provide the most effective cytotoxic chemotherapy partner for anti-EGFR therapies in EGFR CNG-positive advanced ESCC. Combination of gefitinib and platinum-based cytotoxics was antagonistic suggesting anti-EGFR therapies might reduce anti-cancer effects of chemotherapy which could provide a key explanation for the lack of benefit for the addition of anti-EGFR therapies to PBC in randomised clinical trials. Our data suggest that 
the combination of docetaxel with anti-EGFR therapies, with careful consideration of dosing schedules, should be evaluated in advanced EGFR CNG-positive and/or IHC high EGFR expressing ESCC.

\section{Background}

Oesophageal cancer is the sixth most common cause of death from cancer globally, and squamous cell carcinomas of the oesophagus (ESCC), is the dominant histological subtype of oesophageal cancer worldwide (1). Patients frequently present with advanced disease and, as a result of late stage diagnosis and limited treatment options, five-year survival rates remain low at around $15 \%$ (2). Current treatments depend on the tumour stage, co-morbidities and patient performance status; surgery is curative in fewer than half of patients and the majority of patients receive palliative treatment, including chemotherapy (3). Currently, cytotoxic chemotherapy provides a systemic therapy option for palliative treatment of ESCC, but there are no licenced targeted therapies or predictive biomarkers and therefore an unmet need for more effective approaches (4). First-line palliative chemotherapy usually involves a fluoropyrimidine/platinum combination but, eventually, all patients will develop progressive disease with some receiving second-line treatment with a taxane or irinotecan monotherapy (5). Recently, a study in predominantly Asian patients progressing after fluoropyrimidine/platinum chemotherapy demonstrated that the PD-1 inhibitor nivolumab improved overall survival compared to taxane monotherapy [ATTRACTION-3 trial (6)]. Although the progression free survival and the proportion of patients responding were similar in both groups, the responses to nivolumab were more durable but took longer to occur than responses to taxanes. These findings highlight the importance of identifying the minority subgroup of patients who would benefit long-term from nivolumab, however, in the short term, taxanes are superior, highlighting the remaining relevance of taxanes as a treatment option for those patients refractory to first line fluoropyrimidine/platinum chemotherapy. Nevertheless, the low objective response rate $(20 \%)$ and poor long-term survival with taxanes in this setting, indicates that treatment resistance is a major clinical challenge that needs to be addressed.

One approach to develop novel therapies is to identify and target oncogenic drivers and efforts to characterise genome alterations within tumour tissue is now enabling the selection of biomarkers for precision medicine targeted therapies. Although the age-related accumulation of somatic mutations in healthy oesophageal tissue confounds the study of the mutational landscape of oesophageal cancer (7), potential drivers of oesophageal tumourigenesis have been identified, which include the epidermal growth factor receptor (EGFR). EGFR is overexpressed in around $50 \%$ of ESCC tumours compared with normal oesophageal tissue, copy number gain is detected in around $20 \%$ of tumours (8-12) and overexpression of EGFR correlates significantly with tumour invasion (9). EGFR (or ERBB1) is a member of a family of closely related tyrosine kinase receptors which includes HER2 (ERBB2), HER3 (ERBB3) and HER4 (ERBB4). In oesophageal cancer, EGFR is rarely mutated (13), but, receptor overexpression results in ligand-dependent receptor homo- or heterodimerisation leading to activation of down-stream MAPK and PI3-Kinase/AKT signalling cascades and to the promotion of cell proliferation and survival (14). Targeting EGFR with EGFR tyrosine kinase inhibitors (TKi), such as gefitinib, erlotinib or afatinib, inhibits the proliferation of oesophageal cancer cell lines in vitro (15-17), but, clinical trials of EGFR inhibitors in 
oesophageal cancer, including ESCC, have shown mixed results. Monotherapy trials in unselected patients with EGFR inhibitors indicate that there is an EGFR-driven minority ESCC subgroup who gain survival, symptomatic control and health-related quality of life benefits from EGFR inhibitors (18-21). In ESCC, EGFR copy number gain assessed by FISH, and/or EGFR protein over-expression have shown promise as predictive biomarkers to identify this benefiting subgroup, but needs prospective validation (4, $10,22,23)$. Cell line models and patient-derived xenografts also demonstrate an EGFR-driven subgroup of ESCC sensitive to EGFR inhibitors and characterised by EGFR CNG and/or EGFR protein over-expression. However, even in these biomarker selected groups, intrinsic and acquired resistance to EGFR inhibitors remains significant $(15,24,25)$. The considerable heterogeneity of EGFR CNG and protein over-expression observed in ESCC may be a key determinant of resistance (26), with rapid selection and outgrowth occurring of EGFR CNG and protein overexpression-negative tumour cell sub-clones that are unresponsive to EGFR inhibitors. This emphasises the importance of combining EGFR inhibitors with a therapy that is effective against EGFR 'negative' sub-clones, and ideally one that would also synergise with EGFR inhibitors towards the EGFR 'positive' driven sub-clones. To address this, a number of clinical trials have investigated the combination of EGFR inhibitors and cytotoxic chemotherapy. Clinical trials combining EGFR inhibitors and platinum/fluoropyrimidine chemotherapy in the advanced stage setting or with platinum fluoropyrimidine-based concurrent chemoradiotherapy in the curative treatment setting, have not shown an incremental benefit (27). In the largest randomised trial in ESCC, in molecularly unselected patients with advanced stage disease, the addition of the EGFR monoclonal antibody pantitumumab to cisplatin and 5FU chemotherapy did not improve overall survival (28). Similarly, in unselected advanced stage gastroesophageal adenocarcinoma (GOA) patients a negative impact on overall survival was observed with addition of panitumumab to epirubicin, oxaliplatin and capecitabine $(29,30)$. Conflicting results have also been reported in trials of platinum-based chemotherapy in combination with EGFR TKi in non-small cell lung cancer patients (NSCLC) (31-34). In contrast, the addition of the EGFR TKi erlotinib, to definitive chemoradiotherapy for ESCC, which included a taxane (paclitaxel and cisplatin) was beneficial (35).

These conflicting results with EGFR inhibitors in combination with chemotherapy in ESCC could be a consequence of treatment of biomarker unselected patient cohorts. However, negative clinical trial data have also raised questions regarding potential antagonistic effects of co-administration of EGFR inhibitors with cytotoxic chemotherapy (36-39). Overall, there is evidence of an EGFR-driven and EGFR inhibitor-responsive subgroup of ESCC and, thus, the potential to combine current standard of care cytotoxic chemotherapies with EGFR inhibitors to improve outcomes. However, conflicting clinical trial data, the risk of drug antagonism and lack of patient selection in clinical trials have hampered the development and clinical use of EGFR inhibitors for oesophageal cancer. Furthermore, the clinical relevance of this is increased by findings which suggest that, consistent with observation in other tumour types, EGFR signalling is a key determinant of resistance to immune checkpoint inhibitors in ESCC (40), and accordingly EGFR-driven ESCC are likely to be a subgroup that derive less, or no, benefit from immune checkpoint inhibitors. 
To address this, and to identify the drug combinations most likely to benefit ESCC patients, in this study we have investigated the outcomes from platinum/fluoropyrimidine chemotherapy in EGFR CNG positive and negative gastroesophageal cancer patients and then the combinatorial activity of EGFR inhibitors with cytotoxic drugs in ESCC cell lines with EGFR CNG and varying intrinsic sensitivity to gefitinib. Cytotoxic drugs included platinum-based chemotherapies (cisplatin and oxaliplatin), a taxane (docetaxel) and a topoisomerase inhibitor (irinotecan) which were tested in concurrent and sequential administration settings.

\section{Methods}

\section{Patients and tumour samples}

EGFR FISH was performed, to classify tumours as EGFR copy number gain (CNG) positive (high polysomy or amplification) or EGFR CNG negative (EGFR disomy, low trisomy, high trisomy and low polysomy) as described previously (26), on formalin-fixed paraffin embedded tumour samples from the following patient cohorts (Table 1). Firstly, a consecutive cohort of 52 patients with advanced stage (TNM version 7), gastroesophageal cancer treated with platinum/fluoropyrimidine-based palliative chemotherapy in 2015 at Tayside Cancer Centre (Table 1). All patients received up to 6 cycles of epirubicin $50 \mathrm{mg} / \mathrm{m}^{2}$ intravenously, day 1 cisplatin $60 \mathrm{mg} / \mathrm{m}^{2}$ or oxaliplatin $130 \mathrm{mg} / \mathrm{m}^{2}$ intravenously on day 1 , plus capecitabine $1250 \mathrm{mg} / \mathrm{m}^{2}$ orally days $1-21$ as 2 divided doses, or a continuous intravenous infusion of 5 -fluorouracil $200 \mathrm{mg} / \mathrm{m}^{2} / 24$ hours, days $1-21$ on a 21 day cycle. Secondly, a consecutive cohort of 250 patients with operable gastroesophageal cancer (TNM version 7) treated with surgical resection $+/$ - perioperative chemotherapy with 3 cycles before surgery and 3 cycles after surgery of: epirubicin $50 \mathrm{mg} / \mathrm{m}^{2}$ intravenously on day 1 , cisplatin $60 \mathrm{mg} / \mathrm{m}^{2}$ intravenously on day 1 , plus capecitabine $1250 \mathrm{mg} / \mathrm{m}^{2}$ orally days $1-21$ as 2 divided doses, or a continuous intravenous infusion of 5-fluorouracil $200 \mathrm{mg} / \mathrm{m}^{2} / 24$ hours on days 1-21 on a 21-day cycle (Table 1) between 2004 and 2009 in Ninewells Hospital Dundee or Aberdeen Royal Infirmary. The use of all tumour specimens and clinical data was consistent with the patient consent provided and was approved by the appropriate UK regional research ethics committees prior to the work being undertaken. 
Table 1

Clinical features of patients.

\section{(a) Neoadjuvant Cohort}

\section{Clinical Feature}

Age, mean (SD)

Sex, No. (\%)

Male

Female

Histological Diagnosis, No. (\%)

Squamous

Adenocarcinoma

Other

Disease site, No. (\%)

Oesophageal

Junctional

Gastric

Stage, No. (\%)

I

II

III

IV

Neoadjuvant chemotherapy, No.

(\%)

Yes

No
EGFR copy number gain

$\mathrm{N}=\mathbf{4 0}$

$64.3(10.1)$

25 (62.5\%)

$15(37.5 \%)$

$8(20 \%)$

18 (16.6\%)

0.51

$31(77.5 \%)$

$1(2.5 \%)$

$83(76.1 \%)$

$8(7.3 \%)$

p gain

$\mathrm{N}=109$

$64.9(9.4)$

$72(66 \%)$

$37(37 \%)$
0.733

0.687

0.114

$23(57.5 \%)$

$53(48.6 \%)$

$16(14.7 \%)$

$40(36.7 \%)$

$16(40 \%)$

$19(17.4 \%)$

0.90

$34(31.2 \%)$

$53(48.6 \%)$

$3(2.8 \%)$

$11(27.5 \%)$

$20(50 \%)$

$2(5 \%)$
$29(72.5 \%)$

$11(27.5 \%)$
$71(65.1 \%)$

$38(34.9 \%)$

(b) Advanced stage cohort

\section{Clinical Feature}

Age, mean (SD)
EGFR Copy Number

Gain

$\mathrm{N}=\mathbf{2 5}$

$63.1(9.6)$
EGFR no copy number gain

$\mathrm{N}=\mathbf{2 7}$

$59.7(8.8)$

0.191 


\section{(a) Neoadjuvant Cohort}

$\begin{array}{llll}\text { Sex, No. (\%) } & 22(88 \%) & 18(67 \%) & 0.068 \\ \text { Male } & 3(12 \%) & 9(33 \%) & \\ \text { Female } & & & \\ \text { Histological Diagnosis, No. (\%) } & 5(20 \%) & 6(22.2 \%) & 19(70.3 \%) \\ \text { Squamous } & 19(76 \%) & 2(7.4 \%) & 0.647 \\ \text { Adenocarcinoma } & 1(4 \%) & & \\ \text { Other } & & 19(70.3 \%) \\ \text { Disease site, No. (\%) } & 19(76 \%) & 8(29.6 \%) & 0(0 \%) \\ \text { Oesophageal } & 6(24 \%) & \\ \text { Junctional } & 0(0 \%) & 6(22.2 \%) & 0.33 \\ \text { Gastric } & & 21(77.8 \%) & \\ \text { Stage, No. }(\%) & 3(12 \%) & \end{array}$

\section{Cell Lines}

Human KYSE520, OE21, and TE8 oesophageal squamous carcinoma cells (ESCC) with 14, 14, and 11 EGFR CNG, respectively, were obtained from the Cell Resource Center for Biomedical Research, Institute of Development, Aging and Cancer, Tohoku University, Japan. The cell lines were passaged in Roswell Park Memorial Institute RPMI medium 1640 supplemented with L-glutamine (GIBCO) and 10\% foetal bovine serum (FBS) (GIBCO). Cells were tested negative for mycoplasma by the in-house testing facility (Mycoalert) and were authenticated by STR profiling (NorthGene Ltd, Newcastle UK).

\section{Reagents}

Stock solutions were prepared as follows: Gefitinib (Iressa) (Tocris), 20 mM in DMSO; cisplatin (cisDiamineplatinum (II) dichloride, (Sigma Adrich), $3 \mathrm{mM}$ in sterile PBS; oxaliplatin (Selleckchem), $10 \mathrm{mM}$ in sterile water; docetaxel (Selleckchem), $20 \mu \mathrm{M}$ in DMSO and irinotecan (Tocris) (SN-38 - active metabolite of CPT-11), $20 \mathrm{mM}$ in DMSO.

\section{Cell Proliferation Assays}


1000 (OE21, KYSE520, and TE8) viable cells/well were seeded overnight in 96-well plates. Cells were then treated with either solvent control or two- or four-fold dilutions of gefitinib, docetaxel, cisplatin, oxaliplatin or SN-38 (active metabolite of irinotecan). Where possible, drug titrations used were selected to be within the range of peak plasma concentrations of each drug: gefitinib - 1-1.4 $\mu \mathrm{M}(41)$, oxaliplatin $-3.6 \mu \mathrm{M}$ (42), cisplatin - $165 \mu \mathrm{M}$ (43), docetaxel $-4 \mu \mathrm{M}$ (44), SN-38-0.03-0.17 $\mu \mathrm{M}$ (45). The relative insolubility of cisplatin in PBS restricted its maximum working concentration $(40 \mu \mathrm{M})$ to below peak plasma levels. Proliferation assay endpoints (control wells $80 \%$ confluent during log-phase growth) were analysed by CellTitre-Glo ${ }^{\circledR}$ luminescent cell viability assay (Promega) according to the manufacturers' instructions.

\section{Cell Death Assays}

The proportion of dead cells was determined by CellTox ${ }^{\mathrm{TM}}$ Green cytotoxicity assay reagent (Promega) by imaging prior to, and following, addition of $50 \mu \mathrm{L}$ triton-x aqueous permeabilising solution $(0.2 \%)$; nonviable cells were first labelled with CellTox ${ }^{\text {TM }}$ Green cytotoxicity assay reagent (Promega) $(4 \mu \mathrm{L} / \mathrm{mL}$, $10 \mu \mathrm{L} /$ well) and monitored during a drug treatment time course by IncuCyte ${ }^{\circledR}$ Zoom real-time imaging and software (Essen Biosciences, Sartorius). The total number of cells was then determined by permeabilisation/dye-uptake and imaging after triton addition and the equation (first reading/second reading) $* 100$.

\section{Drug Co-administration.}

Studies were designed to conform to the requirements outlined for analysis by the Chou-Talalay mathematical model of drug combinations (46), namely, that combination drugs were used at equimolar dilution ratios at predetermined concentrations where they had an effect on cell growth (around the IC $\mathrm{C}_{50}$ values determined by prior CellTitre-Glo® cell proliferation assays). Cells were seeded at $1000 \mathrm{cells} /$ well in 96-well plates, divided into four groups and treated over 4-days duration as follows: Solvent control group; Gefitinib alone; Cytotoxic drug alone; Concurrent group (gefitinib plus cytotoxic). Cell proliferation was assessed by CellTitre-Glo® assay.

\section{Sequential drug administration study design.}

Cells were seeded overnight and were divided into six groups for treatment 96 hours duration as follows: (i) solvent control group (ii) cytotoxic drug alone group - cells were treated continuously with docetaxel, cisplatin or oxaliplatin (iii) gefitinib alone group - cells were treated continuously with gefitinib (iv) cytotoxic drug followed by gefitinib group - cells were incubated with docetaxel or cisplatin or oxaliplatin or $48 \mathrm{~h}$ followed by gefitinib for $48 \mathrm{~h}$ ( $\mathrm{v}$ ) gefitinib followed by cytotoxic group - cells were treated with gefitinib for $48 \mathrm{~h}$ followed by docetaxel or cisplatin or oxaliplatin for $48 \mathrm{hrs}$. (vi) concurrent group - cells were incubated concurrently with cytotoxic chemotherapy and gefitinib for 96 hours. All groups were 
retreated with the appropriate drug dilution on each treatment day and drug dilutions in media were balanced for solvent concentration. Cell proliferation was assessed by CellTitre-Glo ${ }^{\circledR}$ assay.

\section{Statistical Analysis}

Survival analysis was performed using IBM SPSS statistics v22 (IBM Corporation, Armonk, NY, USA). Kaplan-Meier and Cox proportional hazards analysis were used for survival analysis and survival time was calculated in days from the date of histological diagnosis until the date of death. All reported Pvalues are two sided. A p-value of $<0.05$ was considered statistically significant.

$\mathrm{IC}_{50}$ values were determined from cell proliferation assays using CalcuSyn (Biosoft Version 2.0) or Graphpad prism software. The anti-proliferative effect of combination treatments was evaluated by determining the drug combination index $(\mathrm{Cl})$. Results were analysed according to the Chou-Talalay method (46) using CalcuSyn software (CalcuSyn, Inc. Paramus, USA)(78) which generates Dm values (IC50), dose response curves and median effect plots. Recommended symbols for describing synergistic, additive or antagonistic effects in drug combination studies analyzed with the $\mathrm{Cl}$ method (CalcuSyn user manual) are given where appropriate. Combination index values are given to 2 decimal places.

\section{Results}

\section{EGFR CNG status and outcomes from Platinum/fluoropyrimidine chemotherapy in gastroesophageal cancer patients.}

Firstly, we investigated the impact of EGFR signalling on clinical chemosensitivity by analysing outcomes in EGFR CNG positive and negative gastroesophageal cancer patients treated with platinumfluoropyrimidine combination chemotherapy (PBC).

EGFR CNG status was not associated with patient clinical features (Table 1). Analysis of the cohort $(\mathrm{n}=$ 52) of advanced gastroesophageal cancer patients treated with palliative PBC revealed that patients with tumours containing amplified EGFR $(\mathrm{n}=13$ ) had longer median survival (315 days, $95 \% \mathrm{Cl} 183.3-446.7$ ) than patients without EGFR CNG (201 days, 95\% Cl 184.1-217.9), $\mathrm{HR}=0.49,95 \% \mathrm{Cl} .23-0.99, \mathrm{p}=0.041$ (Fig. 1A). Shorter survival times compared to amplified EGFR cases, were also noted in patients with high polysomy (defined as having EGFR copy number $\geq 4$ in $\geq 40 \%$ of cells) (26) (Fig. 1B).

Operable patients with EGFR CNG positive tumours (high polysomy or amplification) who received neoadjuvant $\mathrm{PBC}$ had longer overall survival than patients with EGFR CNG positive tumours who did not receive neoadjuvant PBC (Fig. 1C). Patients without EGFR CNG positive tumours had similar overall survival regardless of whether they received pre-operative PBC or not (Fig. 1C). EGFR CNG positive patients who received neoadjuvant $\mathrm{PBC}$ had similar overall survival to those without EGFR CNG, but EGFR CNG positive patients who did not receive neoadjuvant PBC had shorter overall survival (Fig. 1C). 
Overall, this suggests that gastroesophageal cancer patients with EGFR-driven tumours (as identified by EGFR CNG) benefit from, and are more sensitive to, PBC. This implies that therapeutic inhibition of EGFRoncogenic pathways in EGFR CNG positive patients could negatively impact on the expected benefit derived from platinum-based chemotherapy and would be antagonistic. These observations could provide an explanation for negative clinical trials investigating PBC combined with EGFR inhibitors in gastroesophageal cancer.

\section{Combinations of Gefitinib and Cytotoxic chemotherapy in EGFR CNG ESCC cell lines.}

No gastroesophageal adenocarcinoma cell lines with EGFR CNG are available, so to investigate the potential antagonistic interaction between EGFR inhibitors and oxaliplatin and cisplatin, our subsequent experiments focused on ESCC. Three ESCC cell lines with EGFR copy number gain were selected. KYSE520 cells were considered resistant to gefitinib, having an IC50 at around the peak plasma levels (Fig. 2A), while inhibition of proliferation of OE21 and TE8 cells occurred at IC50s of 30-fold and 5-fold lower than peak plasma levels, respectively (Fig. 2B). This range in sensitivity to gefitinib reflected the range in response seen in patients in the clinical setting. We also determined the sensitivity of these cell lines to oxaliplatin, cisplatin, docetaxel and irinotecan (administered as the active metabolite SN38) (Fig. 2C and 2D). KYSE520 cells were also least sensitive to cytotoxic agents in agreement with genomics of drug sensitivity in cancer data (https://www.cancerrxgene.org) while TE8 and OE21 cells were relatively sensitive (Fig. 2D).

Having determined the dose response of the agents, we conducted combination experiments in gefitinib sensitive (OE21, TE8) and resistant (KYSE520) cells using drug titrations at equimolar ratios (representative dose responses in OE21 and LYSE520 cells are shown in Fig. 3A) and then calculated combination indices using CalcuSyn software based on Chou-Talalay methodology. Mean ED75 combination indices \pm s.d. from independent experiments are summarised in Fig. 3B. Consistent with our observations in gastroesophageal cancer patients, platinum-based cytotoxic drugs, cisplatin and oxaliplatin, frequently had antagonistic activity when used in combination with gefitinib $(\mathrm{Cl}>1)$. The level of antagonism varied the with agent and cell line. Both cisplatin and oxaliplatin were antagonistic in combination with gefitinib in OE21 cells, the line most sensitive to gefitinib as a monotherapy. SN38 combined with gefitinib induced responses ranging from nearly additive to synergistic. This observation is consistent with reports of synergistic interactions between irinotecan and gefitinib in colorectal cancer cell lines (47). Docetaxel plus gefitinib, however, consistently showed synergistic activity across the cell line panel, and was highly effective at inhibiting the proliferation of the previously gefitinib refractory cell line KYSE520.

We also tested docetaxel and gefitinib as monotherapy and combination therapy in kinetic cell death assays in OE21 and KYSE520 cells over increasing doses (dose 1-4) (Fig. 4). As expected, gefitinib induced little cell death over the four day time course in line with its primary mode of action being 
induction of $\mathrm{G}_{1}$ cell cycle arrest. Docetaxel induced dose-dependent increases in cell death in both cell lines. When docetaxel and gefitinib were used in combination, synergistic levels of cell death were induced (Fig. 4C and 4D) and with more rapid kinetics (Fig. 4A).

These results indicated that gefitinib in combination with docetaxel had the most consistent activity in ESCC inducing synergistic effects on proliferation and cell death. To determine whether synergistic effects could be affected by dosing schedules we tested gefitinib and docetaxel in sequential treatments over 96 hours, $D-G$ = docetaxel followed by gefitinib; $G-D=$ gefitinib followed by docetaxel and compared the effects on cell proliferation of concurrent (combination) gefitinib and docetaxel treatment (Fig. 5). As confirmation of our previous results, concurrent administration of gefitinib and docetaxel induced synergistic inhibition of proliferation of all three cell lines at ED50, ED75 and ED90. Similar results were noted when docetaxel was given prior to gefitinib (schedule $D-G$ ). However, there was a striking shift in response when gefitinib was given prior to docetaxel $(G-D)$. Administered sequentially, gefitinib followed by docetaxel was antagonistic in all three cell lines, suggesting that careful dosing schedules should be devised to avoid deleterious drug interactions.

\section{Discussion}

Oesophageal Squamous cell carcinoma (ESCC) patients whose tumours have EGFR CNG and/or EGFR protein overexpression may represent a subgroup that benefits from EGFR inhibitor monotherapy $(10,22$, 23). However, even in this biomarker selected subgroup of ESCC, significant proportions of patients do not respond to EGFR inhibitors and durable responses are uncommon, indicating that primary and acquired clinical resistance is a major clinical challenge. Heterogeneity is a predominant feature of ESCC, including for EGFR CNG and protein over-expression. Tumours with a higher number of genomic clonal subpopulations that are not EGFR-driven are less likely to respond significantly to monotherapy with an EGFR inhibitor. Therefore, EGFR combination treatments are likely to be important to optimise treatment effectiveness in EGFR CNG positive ESCC.

Several clinical trials have investigated the combination of EGFR inhibitors with cytotoxic chemotherapy or concurrent chemoradiotherapy $(27-30,35)$. In the palliative setting, in both ESCC and GOA the addition of EGFR inhibitors to platinum plus fluoropyrimidine chemotherapy has not improved overall survival $(28-30)$. Similarly, in the radical treatment setting, the addition of EGFR inhibitors to concurrent chemoradiotherapy, with a platinum and fluoropyrimidine chemotherapy backbone has not improved overall survival (27). However, addition of EGFR inhibition to chemoradiotherapy in ESCC with a chemotherapy backbone incorporating paclitaxel did improve overall survival, even in biomarker unselected patients (35). Consistent with these clinical trial results we observed that EGFR CNG positive gastroesophageal cancers in both the palliative and neoadjuvant setting appear to be more sensitive to platinum fluoropyrimidine-based cytotoxic chemotherapy. This suggests that the use of an EGFR inhibitor could reduce, or negate, the benefit of platinum-based cytotoxic chemotherapy in patients with EGFRdriven tumours and would thus be antagonistic. We confirmed this in EGFR CNG cell lines. Because no 
GOA cell lines with EGFR CNG are available, our cell line experiments were restricted to ESCC. This is a limitation of our work. Deriving EGFR CNG GOA cell lines would be advantageous.

Our data suggesting that the combination of gefitinib with cisplatin is antagonistic (in TE8 and OE21 cells) are at odds with reports that treatment of TE8 xenograft tumours with cisplatin in combination with EGFR inhibition by cetuximab significantly reduces their size (48). Such discrepancies may arise due to the nature of the mechanism of inhibition of EGFR (small molecule EGFR TKi versus blocking antibody with potential antibody-dependent cellular cytotoxicity effects). However, clinical results of EGFR monoclonal antibodies both as monotherapy and in combination with PBC in ESCC have been similar to those demonstrated with EGFR TKis $(10,18,20-23,27,28,35)$. In addition, in line with our conclusions, the POWER phase III RCT in advanced ESCC did not demonstrate any benefit of the addition of the humanised monoclonal anti-EGFR antibody panitumumab to cisplatin plus fluoropyrimidine chemotherapy (28). POWER enrolled molecularly unselected ESCC patients, but, a retrospective analysis demonstrated that EGFR IHC did not correlate significantly with overall survival, and EGFR copy number was not investigated. The antagonism between cisplatin and oxaliplatin and EGFR inhibition provides a key explanation for this, and other, negative clinical trials and suggests that, even if these trials had been undertaken in biomarker selected patients, benefit from the addition of EGFR inhibitors may not have been observed.

Previous studies in KYSE30 cells have suggested that the sequence of administration of gefitinib in combination with cytotoxic agents determines efficacy. Synergy was noted with cisplatin, carboplatin, oxaliplatin, docetaxel and paclitaxel followed by gefitinib (49). However, our studies in a wider cell panel suggest that the effect of concurrent gefitinib with platinum-based cytotoxic drugs is cell line-dependent and thus the effects of this combination may be unpredictable in the clinical setting. In contrast, we demonstrated that gefitinib and docetaxel was consistently synergistic. This observation is consistent with the demonstration that addition of erlotinib to chemoradiotherapy including paclitaxel was beneficial in ESCC (35). In this study there was no biomarker selection, and we hypothesise that in this trial the greatest benefit from addition of erlotinib will be seen in those patients who are EGFR CNG and/or have EGFR protein overexpression.

Our results suggest that the combination of a taxane and EGFR inhibitor should be evaluated in ESCC. However, our cell line studies also suggest that the sequence of administration of taxane and EGFR inhibitor is critical. The administration of gefitinib prior to docetaxel invariably resulted in antagonism which is consistent with studies in both an NSCLC cell line (50) and in KYSE30 ESCC cells (49). This data suggests that careful scheduling, or drug holidays would be required to avoid possible antagonistic drug interactions. When used in combination with paclitaxel, pulsatile administration of gefitinib has proved more effective than continuous dosing in murine models of breast cancer, (51).

The molecular mechanism of drug combination antagonism or synergy in this setting is unclear and is under investigation. In vitro studies analysing potential combination therapies on both head and neck SCC and NSCLC cell lines suggest that there is also antagonism between gefitinib and cisplatin in other 
tumour types (36-38); the effects have been variously attributed to cisplatin cytotoxicity being dependent on EGFR phosphorylation and degradation (39), induction of epithelial to mesenchymal transition (EMT) which is associated with increased resistance to gefitinib (37), reduced cisplatin entry into the cell and increased DNA repair or cell cycle arrest in $G_{1}$. However, antagonism can be overcome by concurrent use of autophagy inhibitors (without any apparent effect on the cell cycle) (38) suggesting that factors other than the phase of the cell cycle may be involved, for example, secretion of exosomes from gefitinibtreated cells is reported to increase autophagy and increase resistance to cisplatin in PC9 lung cancer cells (52). Previous reports in colorectal cancer cells have suggested that treatment of cells with cytotoxic agents increases phosphorylation of EGFR rendering cells more sensitive to the effects of EGFR TKis, whereas, antagonistic interactions result from a cytotoxic drug induced decrease in EGFR phosphorylation $(47,53)$ In NSCLC, the mechanism of synergistic interaction was also suggested to be due to increased docetaxel-induced phosphorylation of EGFR and its subsequent inhibition following gefitinib addition (9), however, similar analysis of our ESCC cell lines over several repeat experiments were inconclusive. The antagonistic effect of sequential administration of gefitinib prior to docetaxel could be due to cell cycle effects where gefitinib induces a G1 cell cycle arrest thus rendering taxanes (which are primarily mitotic spindle inhibitors acting in $\mathrm{G} 2 / \mathrm{M}$ ) ineffective $(49,50)$. Since concurrent administration of gefitinib or administration after docetaxel is synergistic, in the clinic, this would suggest that an interrupted schedule of an oral TKi like gefitinib, would be needed in combination with a taxane. Alternatively, and in contrast to common clinical practice at present, an EGFR monoclonal antibody should be administered after docetaxel and not before, when combined with a taxane.

Recently, the ATTRACTION-3 study demonstrated that the PD-1 inhibitor nivolumab provided improved overall survival compared to taxane monotherapy suggesting that nivolumab is a new standard of care for ESCC after progression with fluoropyrimidine/platinum chemotherapy (6). However, given that only a minority subgroup of patients respond to nivolumab and responses took a median of 2.6 months to occur, its use presents clinical challenges in this setting where patients often have high tumour burdens and are very symptomatic. In addition, in squamous cell carcinomas including ESCC, EGFR activation is associated with depleted tumour infiltrating lymphocytes and resistance to immune checkpoint inhibition (ICI) (40). EGFR activation leads to increased anaerobic glycolysis in tumour cells, glucose depletion and accumulation of lactate in squamous cell carcinomas, meaning that tumour-infiltrating $T$ cells, may have to compete for metabolic fuels. ICl appear to be less effective in EGFR mutant positive NSCLC $(40,54)$, and EGFR activation has been associated with hyper-progression following ICI therapy (55). Early phase trials in NSCLC have revealed problematic toxicity combining EGFR inhibitors and immune checkpoint inhibitors (56). Together these data suggest that EGFR-driven ESCC, identified by EGFR CNG and /or EGFR protein overexpression are likely to be less sensitive to nivolumab which is unlikely as a monotherapy to provide an effective treatment for this group of patients. As such, taxanes will likely remain one standard of care for ESCC after progression with fluoropyrimidine/platinum chemotherapy, either before or after nivolumab. Overall, our results contribute additional evidence to support investigation of EGFR inhibitors in EGFR CNG positive ESCC and suggest that a combination strategy with taxanes has the potential for synergism thereby optimising clinical impact and effectiveness. Since 
taxanes are a standard of care for ESCC after progression with fluoropyrimidine/platinum chemotherapy evaluating the benefit of the addition of an EGFR inhibitor to docetaxel or paclitaxel in tumours that are EGFR CNG and/or EGFR protein overexpressed by IHC would be the most appropriate initial area of clinical investigation.

\section{Conclusions}

Drug combination studies indicate that targeting EGFR in ESCC cells carrying EGFR copy number gain may negate or reduce anticancer effects of platinum-based chemotherapy, however, EGFR inhibitors are efficacious and synergistic in combination with docetaxel when scheduled correctly. We recommend clinical investigation of scheduled anti- EGFR therapies combined with taxanes for ESCC patients with tumours expressing high EGFR by IHC and/or have EGFR CNG.

\section{Abbreviations}

ESCC, oesophageal squamous cell carcinoma. EGFR, epidermal growth factor receptor. CNG, copy number gain. EAC, oesophageal adenocarcinoma. NSCLC, non-small cell lung cancer. IHC, immunohistochemistry. SD, standard deviation. ICl, immune checkpoint inhibition. TKi, tyrosine kinase inhibitor. EMT, epithelial to mesenchymal transition. GOA, gastroesophageal adenocarcinoma. $\mathrm{Cl}$, combination index. PBC, platinum-fluoropyrimidine combination chemotherapy.

\section{Declarations}

\section{Ethics approval and consent to participate:}

Ethical approval for use of human tissue in this study was obtained from the Scientific Access Committees of the Grampian Tissue Biorepository and the Tayside Biorepository. The Biorepositories have delegated research ethics authority from The North of Scotland research ethics committee (Grampian) and the East of Scotland research ethics committee (Tayside) to approve research projects involving human tissue and data. All tissue and data were anonymised. Project specific written consent was not required for the retrospective use of archival tissue. The study was performed in accordance with the Declaration of Helsinki.

\section{Consent for publication:}

Not applicable

\section{Availability of data and materials:}

All data reported in this manuscript are included in the figures and tables. 


\section{Competing interests:}

RDP has undertaken speaking, consulting and advisory roles for Eli Lilly, BMS, Pfizer, Sanofi, Servier; and received research funding (not related to the work in this manuscript) from Astra Zeneca, Roche, MSD, Merck serrano, Eli Lilly, Five Prime Therapeutics, Clovis, Boston Biomedical, and Janssen.

\section{Funding:}

The work undertaken was funded by Ninewells Cancer Campaign (Dundee) and Scottish Government Chief Scientist Office (Grant reference TCS/19/18).

\section{Authors' contributions:}

LCS designed and conducted experiments, analysed data and prepared the manuscript. MM, PC, and JI designed, conducted and analysed experiments. MB analysed clinical data. JT and CC conducted experiments. GM and SW prepared and analysed clinical samples. DC conducted experiments and analysed data. ZM designed experiments. RP designed experiments, analysed data and prepared the manuscript.

\section{Acknowledgements:}

We thank Alice Savage for technical laboratory assistance.

\section{References}

1. Jemal A, Center MM, DeSantis C, Ward EM. Global patterns of cancer incidence and mortality rates and trends. Cancer Epidemiol Biomarkers Prev. 2010;19(8):1893-907.

2. Arnold M, Rutherford MJ, Bardot A, Ferlay J, Andersson TM, Myklebust TA, et al. Progress in cancer survival, mortality, and incidence in seven high-income countries 1995-2014 (ICBP SURVMARK-2): a population-based study. Lancet Oncol. 2019;20(11):1493-505.

3. www.nogca.org.uk. Healthcare Quality Improvement Partnership (HQIP). An audit of the care received by people with oesophago-gastric cancer and oesophageal high grade dysplasia in England and Wales. Version 2. 2019.

4. Muro K, Lordick F, Tsushima T, Pentheroudakis G, Baba E, Lu Z, et al. Pan-Asian adapted ESMO Clinical Practice Guidelines for the management of patients with metastatic oesophageal cancer: a JSMO-ESMO initiative endorsed by CSCO, KSMO, MOS, SSO and TOS. Ann Oncol. 2019;30(1):34-43.

5. Wang J, Chang J, Yu H, Wu X, Wang H, Li W, et al. A phase II study of oxaliplatin in combination with leucovorin and fluorouracil as first-line chemotherapy in patients with metastatic squamous cell carcinoma of esophagus. Cancer Chemother Pharmacol. 2013;71(4):905-11. 
6. Kato K, Cho BC, Takahashi M, Okada M, Lin CY, Chin K, et al. Nivolumab versus chemotherapy in patients with advanced oesophageal squamous cell carcinoma refractory or intolerant to previous chemotherapy (ATTRACTION-3): a multicentre, randomised, open-label, phase 3 trial. Lancet Oncol. 2019;20(11):1506-17.

7. Martincorena I, Fowler JC, Wabik A, Lawson ARJ, Abascal F, Hall MWJ, et al. Somatic mutant clones colonize the human esophagus with age. Science. 2018;362(6417):911-7.

8. Chang J, Tan W, Ling Z, Xi R, Shao M, Chen M, et al. Genomic analysis of oesophageal squamouscell carcinoma identifies alcohol drinking-related mutation signature and genomic alterations. Nat Commun. 2017;8:15290.

9. Hanawa M, Suzuki S, Dobashi Y, Yamane T, Kono K, Enomoto N, et al. EGFR protein overexpression and gene amplification in squamous cell carcinomas of the esophagus. Int $\mathrm{J}$ Cancer. 2006;118(5):1173-80.

10. Petty RD, Dahle-Smith A, Stevenson DAJ, Osborne A, Massie D, Clark C, et al. Gefitinib and EGFR Gene Copy Number Aberrations in Esophageal Cancer. J Clin Oncol. 2017;35(20):2279-87.

11. Cancer Genome Atlas Research N, Analysis Working Group. Asan U, Agency BCC, Brigham, Women's $\mathrm{H}, \mathrm{Broad} \mathrm{I}$, et al. Integrated genomic characterization of oesophageal carcinoma. Nature. 2017;541(7636):169-75.

12. Yang YL, Xu KL, Zhou Y, Gao X, Chen LR. Correlation of epidermal growth factor receptor overexpression with increased epidermal growth factor receptor gene copy number in esophageal squamous cell carcinomas. Chin Med J (Engl). 2012;125(3):450-4.

13. Guo K, Wang WP, Jiang T, Wang JZ, Chen Z, Li Y, et al. Assessment of epidermal growth factor receptor mutation/copy number and K-ras mutation in esophageal cancer. $J$ Thorac Dis. 2016;8(7):1753-63.

14. Fichter CD, Timme S, Braun JA, Gudernatsch V, Schopflin A, Bogatyreva L, et al. EGFR, HER2 and HER3 dimerization patterns guide targeted inhibition in two histotypes of esophageal cancer. Int $J$ Cancer. 2014;135(7):1517-30.

15. Zhou J, Wu Z, Wong G, Pectasides E, Nagaraja A, Stachler M, et al. CDK4/6 or MAPK blockade enhances efficacy of EGFR inhibition in oesophageal squamous cell carcinoma. Nat Commun. 2017;8:13897.

16. Wong CH, Ma BB, Hui CW, Tao Q, Chan AT. Preclinical evaluation of afatinib (BIBW2992) in esophageal squamous cell carcinoma (ESCC). Am J Cancer Res. 2015;5(12):3588-99.

17. Nakamura Y, Togashi Y, Nakahara H, Tomida S, Banno E, Terashima M, et al. Afatinib against Esophageal or Head-and-Neck Squamous Cell Carcinoma: Significance of Activating Oncogenic HER4 Mutations in HNSCC. Mol Cancer Ther. 2016;15(8):1988-97.

18. Dutton SJ, Ferry DR, Blazeby JM, Abbas H, Dahle-Smith A, Mansoor W, et al. Gefitinib for oesophageal cancer progressing after chemotherapy (COG): a phase 3 , multicentre, double-blind, placebo-controlled randomised trial. Lancet Oncol. 2014;15(8):894-904. 
19. Adelstein DJ, Rodriguez CP, Rybicki LA, Ives DI, Rice TW. A phase II trial of gefitinib for recurrent or metastatic cancer of the esophagus or gastroesophageal junction. Invest New Drugs. 2012;30(4):1684-9.

20. Janmaat ML, Gallegos-Ruiz MI, Rodriguez JA, Meijer GA, Vervenne WL, Richel DJ, et al. Predictive factors for outcome in a phase II study of gefitinib in second-line treatment of advanced esophageal cancer patients. J Clin Oncol. 2006;24(10):1612-9.

21. Ilson DH, Kelsen D, Shah M, Schwartz G, Levine DA, Boyd J, et al. A phase 2 trial of erlotinib in patients with previously treated squamous cell and adenocarcinoma of the esophagus. Cancer. 2011;117(7):1409-14.

22. Wang X, Niu H, Fan Q, Lu P, Ma C, Liu W, et al. Predictive value of EGFR overexpression and gene amplification on icotinib efficacy in patients with advanced esophageal squamous cell carcinoma. Oncotarget. 2016;7(17):24744-51.

23. Huang J, Fan Q, Lu P, Ying J, Ma C, Liu W, et al. Icotinib in Patients with Pretreated Advanced Esophageal Squamous Cell Carcinoma with EGFR Overexpression or EGFR Gene Amplification: A Single-Arm, Multicenter Phase 2 Study. J Thorac Oncol. 2016;11(6):910-7.

24. Zhu H, Wang C, Wang J, Chen D, Deng J, Deng J, et al. A subset of esophageal squamous cell carcinoma patient-derived xenografts respond to cetuximab, which is predicted by high EGFR expression and amplification. J Thorac Dis. 2018;10(9):5328-38.

25. Liu Z, Chen Z, Wang J, Zhang M, Li Z, Wang S, et al. Mouse avatar models of esophageal squamous cell carcinoma proved the potential for EGFR-TKI afatinib and uncovered Src family kinases involved in acquired resistance. J Hematol Oncol. 2018;11(1):109.

26. Dahle-Smith A, Stevenson D, Massie D, Murray GI, Dutton SJ, Roberts C, et al. Epidermal Growth Factor (EGFR) copy number aberrations in esophageal and gastro-esophageal junctional carcinoma. Mol Cytogenet. 2015;8:78.

27. Crosby T, Hurt CN, Falk S, Gollins S, Mukherjee S, Staffurth J, et al. Chemoradiotherapy with or without cetuximab in patients with oesophageal cancer (SCOPE1): a multicentre, phase 2/3 randomised trial. Lancet Oncol. 2013;14(7):627-37.

28. Moehler M, Maderer A, Thuss-Patience PC, Brenner B, Meiler J, Ettrich TJ, et al. Cisplatin and 5fluorouracil with or without epidermal growth factor receptor inhibition panitumumab for patients with non-resectable, advanced or metastatic oesophageal squamous cell cancer: a prospective, open-label, randomised phase III AIO/EORTC trial (POWER). Ann Oncol. 2020;31(2):228-35.

29. Waddell T, Chau I, Cunningham D, Gonzalez D, Okines AF, Okines C, et al. Epirubicin, oxaliplatin, and capecitabine with or without panitumumab for patients with previously untreated advanced oesophagogastric cancer (REAL3): a randomised, open-label phase 3 trial. Lancet Oncol. 2013;14(6):481-9.

30. Lordick F, Kang YK, Chung HC, Salman P, Oh SC, Bodoky G, et al. Capecitabine and cisplatin with or without cetuximab for patients with previously untreated advanced gastric cancer (EXPAND): a randomised, open-label phase 3 trial. Lancet Oncol. 2013;14(6):490-9. 
31. Mok T, Ladrera G, Srimuninnimit V, Sriuranpong V, Yu CJ, Thongprasert S, et al. Tumor marker analyses from the phase III, placebo-controlled, FASTACT-2 study of intercalated erlotinib with gemcitabine/platinum in the first-line treatment of advanced non-small-cell lung cancer. Lung Cancer. 2016;98:1-8.

32. Herbst RS, Prager D, Hermann R, Fehrenbacher L, Johnson BE, Sandler A, et al. TRIBUTE: a phase III trial of erlotinib hydrochloride (OSI-774) combined with carboplatin and paclitaxel chemotherapy in advanced non-small-cell lung cancer. J Clin Oncol. 2005;23(25):5892-9.

33. Herbst RS, Giaccone G, Schiller JH, Natale RB, Miller V, Manegold C, et al. Gefitinib in combination with paclitaxel and carboplatin in advanced non-small-cell lung cancer: a phase III trial-INTACT 2. J Clin Oncol. 2004;22(5):785-94.

34. Takeda $\mathrm{K}$, Hida $\mathrm{T}$, Sato $\mathrm{T}$, Ando $\mathrm{M}$, Seto $\mathrm{T}$, Satouchi M, et al. Randomized phase III trial of platinumdoublet chemotherapy followed by gefitinib compared with continued platinum-doublet chemotherapy in Japanese patients with advanced non-small-cell lung cancer: results of a west Japan thoracic oncology group trial (WJTOG0203). J Clin Oncol. 2010;28(5):753-60.

35. Wu SX, Wang LH, Luo HL, Xie CY, Zhang XB, Hu W, et al. Randomised phase III trial of concurrent chemoradiotherapy with extended nodal irradiation and erlotinib in patients with inoperable oesophageal squamous cell cancer. Eur J Cancer. 2018;93:99-107.

36. Tsai CM, Chen JT, Stewart DJ, Chiu CH, Lai CL, Hsiao SY, et al. Antagonism between gefitinib and cisplatin in non-small cell lung cancer cells: why randomized trials failed? J Thorac Oncol. 2011;6(3):559-68.

37. Kurokawa M, Ise N, Omi K, Goishi K, Higashiyama S. Cisplatin influences acquisition of resistance to molecular-targeted agents through epithelial-mesenchymal transition-like changes. Cancer Sci. 2013;104(7):904-11.

38. Liu JT, Li WC, Gao S, Wang F, Li XQ, Yu HQ, et al. Autophagy Inhibition Overcomes the Antagonistic Effect Between Gefitinib and Cisplatin in Epidermal Growth Factor Receptor Mutant Non-Small-Cell Lung Cancer Cells. Clin Lung Cancer. 2015;16(5):e55-66.

39. Ahsan A, Hiniker SM, Ramanand SG, Nyati S, Hegde A, Helman A, et al. Role of epidermal growth factor receptor degradation in cisplatin-induced cytotoxicity in head and neck cancer. Cancer Res. 2010;70(7):2862-9.

40. Ottensmeier $\mathrm{CH}$, Perry KL, Harden EL, Stasakova J, Jenei V, Fleming J, et al. Upregulated Glucose Metabolism Correlates Inversely with CD8 + T-cell Infiltration and Survival in Squamous Cell Carcinoma. Cancer Res. 2016;76(14):4136-48.

41. Baselga J, Rischin D, Ranson M, Calvert H, Raymond E, Kieback DG, et al. Phase I safety, pharmacokinetic, and pharmacodynamic trial of ZD1839, a selective oral epidermal growth factor receptor tyrosine kinase inhibitor, in patients with five selected solid tumor types. $\mathrm{J}$ Clin Oncol. 2002;20(21):4292-302.

42. Ehrsson H, Wallin I, Yachnin J. Pharmacokinetics of oxaliplatin in humans. Med Oncol. 2002;19(4):261-5. 
43. van Hennik MB, van der Vijgh WJ, Klein I, Elferink F, Vermorken JB, Winograd B, et al. Comparative pharmacokinetics of cisplatin and three analogues in mice and humans. Cancer Res.

1987;47(23):6297-301.

44. Bruno R, Hille D, Riva A, Vivier N, ten Bokkel Huinnink WW, van Oosterom AT, et al. Population pharmacokinetics/pharmacodynamics of docetaxel in phase II studies in patients with cancer. J Clin Oncol. 1998;16(1):187-96.

45. Rivory LP, Haaz MC, Canal P, Lokiec F, Armand JP, Robert J. Pharmacokinetic interrelationships of irinotecan (CPT-11) and its three major plasma metabolites in patients enrolled in phase I/II trials. Clin Cancer Res. 1997;3(8):1261-6.

46. Chou TC, Talalay P. Quantitative analysis of dose-effect relationships: the combined effects of multiple drugs or enzyme inhibitors. Adv Enzyme Regul. 1984;22:27-55.

47. Koizumi F, Kanzawa F, Ueda Y, Koh Y, Tsukiyama S, Taguchi F, et al. Synergistic interaction between the EGFR tyrosine kinase inhibitor gefitinib ("Iressa") and the DNA topoisomerase I inhibitor CPT-11 (irinotecan) in human colorectal cancer cells. Int J Cancer. 2004;108(3):464-72.

48. Kwon J, Yoon HJ, Kim JH, Lee TS, Song IH, Lee HW, et al. Cetuximab inhibits cisplatin-induced activation of EGFR signaling in esophageal squamous cell carcinoma. Oncol Rep. 2014;32(3):118892.

49. Morelli MP, Cascone T, Troiani T, De Vita F, Orditura M, Laus G, et al. Sequence-dependent antiproliferative effects of cytotoxic drugs and epidermal growth factor receptor inhibitors. Ann Oncol. 2005;16(Suppl 4):iv61-8.

50. Chen B, Zheng J, Zeng Y, Li B, Xie B, Zheng J, et al. Sequence-dependent antiproliferative effects of gefitinib and docetaxel on non-small cell lung cancer (NSCLC) cells and the possible mechanism. PLoS One. 2014;9(12):e114074.

51. Solit DB, She Y, Lobo J, Kris MG, Scher HI, Rosen N, et al. Pulsatile administration of the epidermal growth factor receptor inhibitor gefitinib is significantly more effective than continuous dosing for sensitizing tumors to paclitaxel. Clin Cancer Res. 2005;11(5):1983-9.

52. Li XQ, Liu JT, Fan LL, Liu Y, Cheng L, Wang F, et al. Exosomes derived from gefitinib-treated EGFRmutant lung cancer cells alter cisplatin sensitivity via up-regulating autophagy. Oncotarget. 2016;7(17):24585-95.

53. Van Schaeybroeck S, Karaiskou-McCaul A, Kelly D, Longley D, Galligan L, Van Cutsem E, et al. Epidermal growth factor receptor activity determines response of colorectal cancer cells to gefitinib alone and in combination with chemotherapy. Clin Cancer Res. 2005;11(20):7480-9.

54. Tsakonas G, Ekman S. Oncogene-addicted non-small cell lung cancer and immunotherapy. J Thorac Dis. 2018;10(Suppl 13):1547-S55.

55. Kato S, Goodman A, Walavalkar V, Barkauskas DA, Sharabi A, Kurzrock R. Hyperprogressors after Immunotherapy: Analysis of Genomic Alterations Associated with Accelerated Growth Rate. Clin Cancer Res. 2017;23(15):4242-50. 
56. Ahn MJ, Sun JM, Lee SH, Ahn JS, Park K. EGFR TKI combination with immunotherapy in non-small cell lung cancer. Expert Opin Drug Saf. 2017;16(4):465-9.

\section{Figures}

A

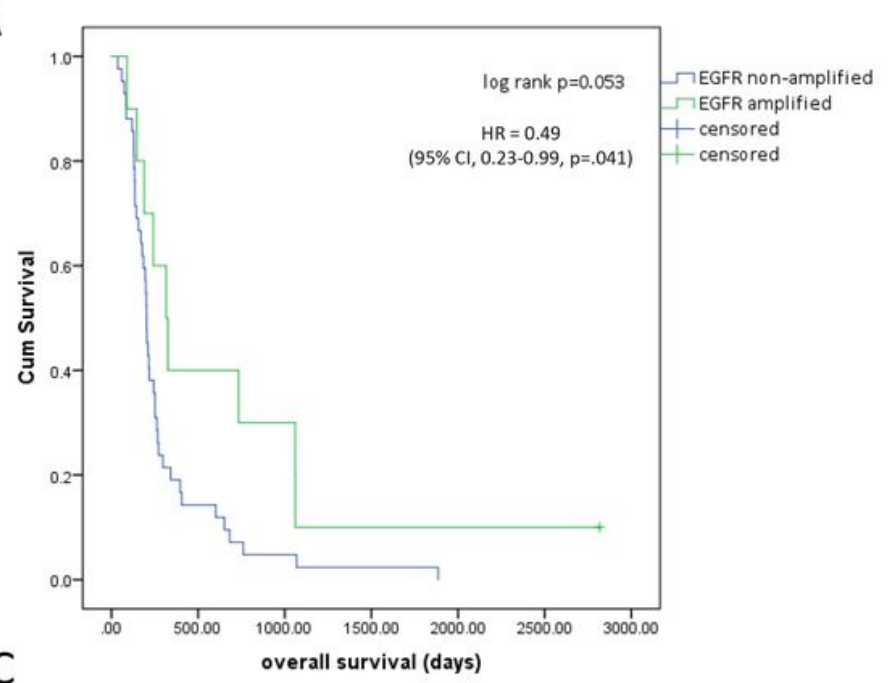

C

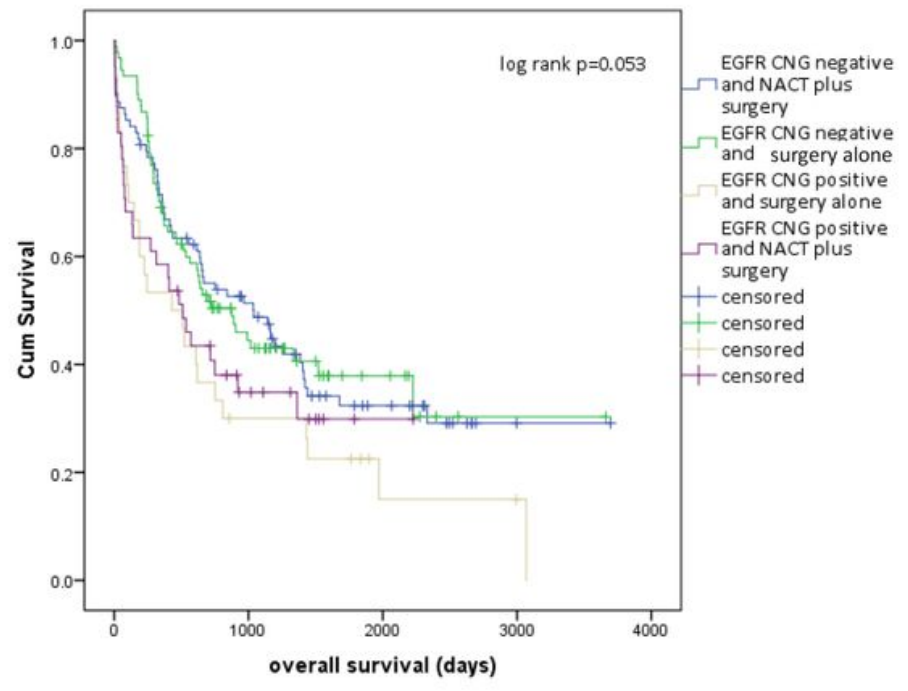

B

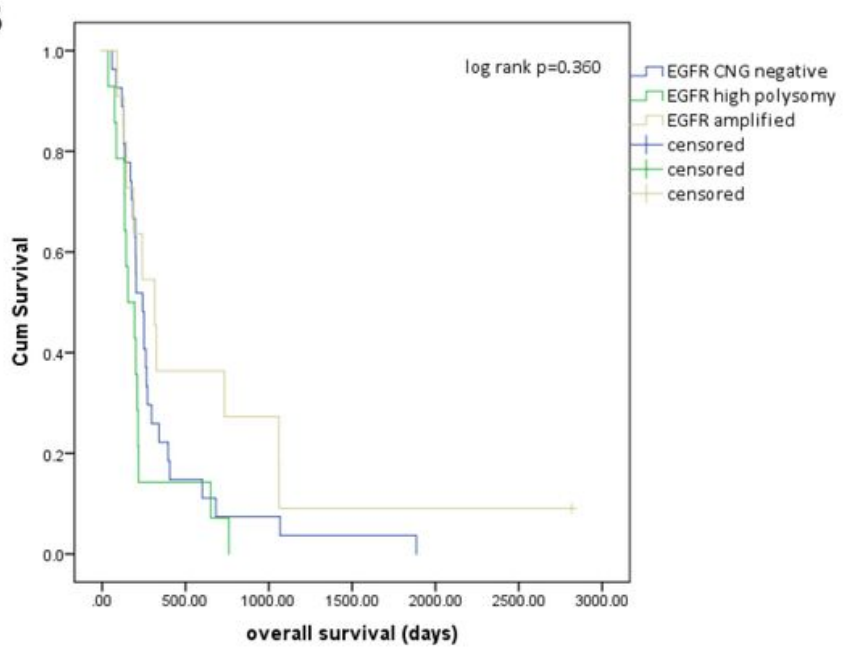

Figure 1

EGFR copy number status and outcome following treatment with platinum-based chemotherapy in gastroesophageal cancers. (A) Advanced stage patients $(n=52)$ treated with palliative platinum-based combination chemotherapy categorised as EGFR amplified and EGFR non-amplified. (B) Advanced stage patients treated with palliative platinum-based combination chemotherapy categorised as EGFR amplified, EGFR high polysomy or EGFR copy number gain negative (CNG negative includes EGFR disomy, low trisomy, high trisomy and low polysomy). (C) Operable gastroesophageal cancers treated with surgical resection alone or platinum-based neo-adjuvant chemotherapy (NACT) followed by surgical resection categorised as EGFR copy number gain positive (CNG positive, includes EGFR amplification and high polysomy), or EGFR CNG negative 
A

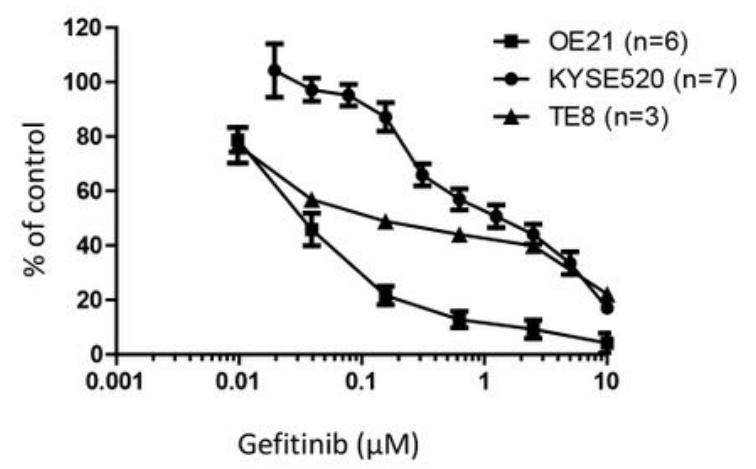

\begin{tabular}{|c|c|c|}
\hline Drug & \multicolumn{2}{|c|}{ Gefitinib } \\
\hline Peak plasma level & \multicolumn{2}{|c|}{$1.07-1.39 \mu \mathrm{M}$} \\
\hline Curve fit & IC50 $(\mu \mathrm{M})$ & $95 \% \mathrm{Cl}$ \\
\hline OE21 & 0.035 & 0.025 to 0.049 \\
\hline TE8 & 0.23 & 0.13 to 0.39 \\
\hline KYSE520 & 1.312 & 1.04 to 1.65 \\
\hline
\end{tabular}
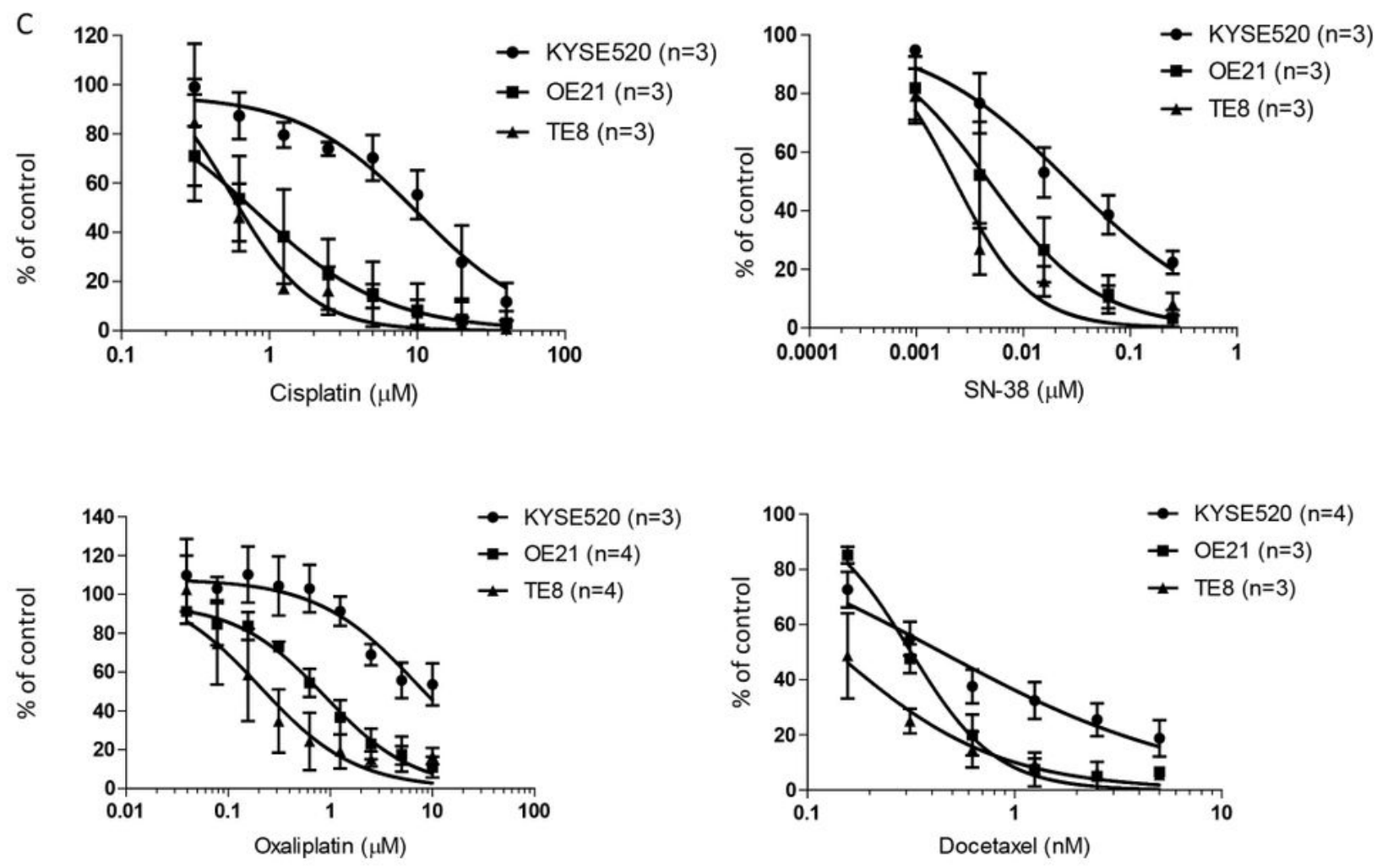

D

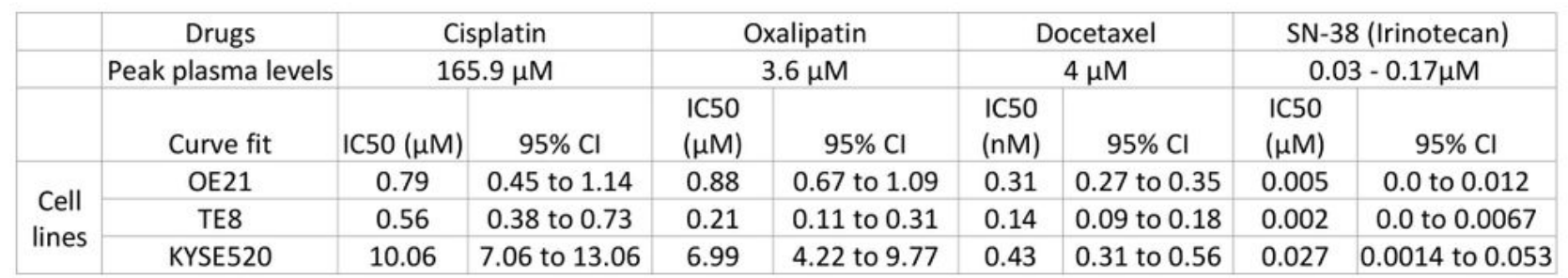

Figure 2

Sensitivity of ESCC cell lines to gefitinib and cytotoxic monotherapy. Dose-response curves (A and C) and IC50s (B and D) for gefitinib (A and B) and cytotoxic agents, cisplatin, oxaliplatin, docetaxel, and irinotecan (C and D) in three ESCC cell lines. (A and C) Cells were seeded overnight in 96-well plates and treated with concentrations of gefitinib, docetaxel, cisplatin, oxaliplatin or SN38 (irinotecan) as indicated. Cells were harvested with CellTitre-glo® assay reagent (Promega) and graphs depict cell proliferation 
relative to solvent control treated cells (set at 100\%). The non-linear curve fit was generated using Graphpad from at least 3 independent assays (n) as indicated in the graph legend. IC50 values and 95\% confidence intervals ( $\mathrm{B}$ and $\mathrm{D}$ ) were determined using graphpad prism. Peak plasma levels are also given for each agent.
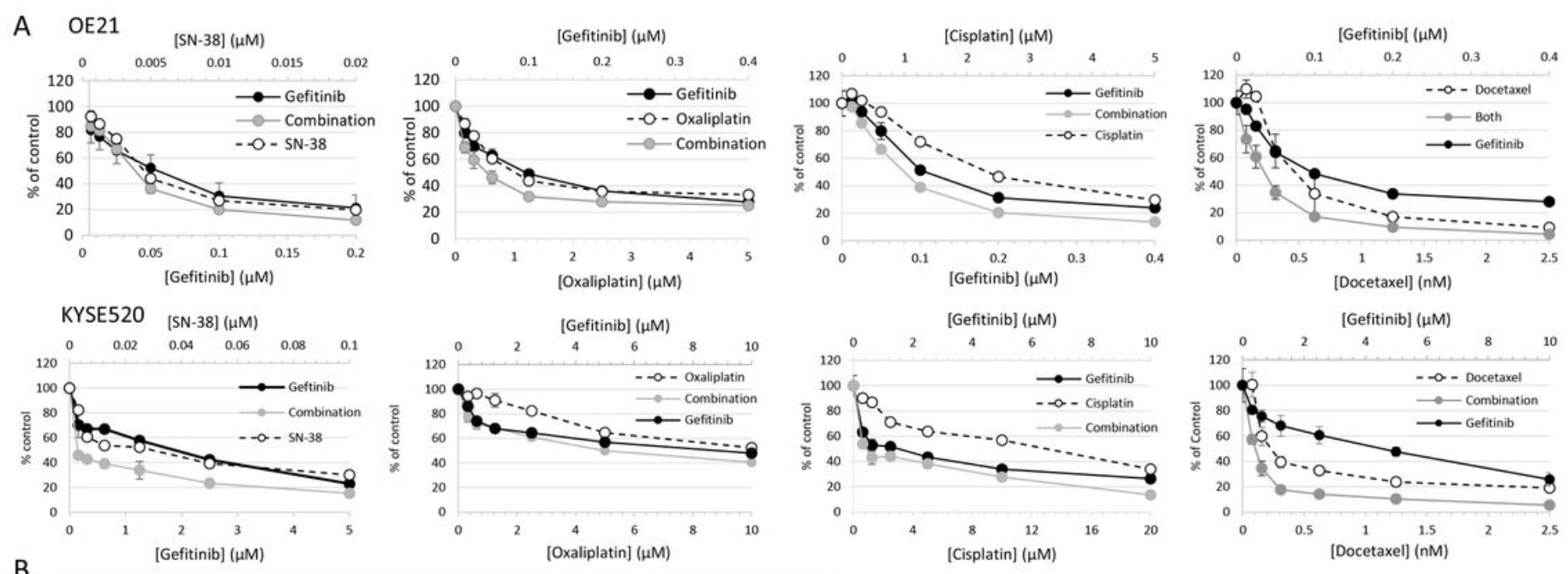

B

\begin{tabular}{|c|c|c|c|c|c|c|c|c|}
\hline & \multicolumn{8}{|c|}{ Mean Combination Indices (ED75) of gefitinib with: } \\
\hline & Docetaxel & $\mathrm{n}$ & Oxaliplatin & $\mathrm{n}$ & Cisplatin & $\mathrm{n}$ & Irinotecan & $\mathrm{n}$ \\
\hline TE8 & $\begin{array}{c}0.72 \pm 0.3 \\
++\end{array}$ & 4 & $\begin{array}{c}0.52 \pm 0.29 \\
+++\end{array}$ & 3 & $\begin{array}{c}1.38 \pm 0.86 \\
\cdots\end{array}$ & 3 & $\begin{array}{c}0.64 \pm 0.12 \\
+++\end{array}$ & 3 \\
\hline OE21 & $\begin{array}{c}0.75 \pm 0.17 \\
++\end{array}$ & 5 & $\begin{array}{c}1.63 \pm 0.48 \\
\ldots\end{array}$ & 3 & $1.16 \pm 0.11$ & 3 & $\begin{array}{c}0.98 \pm 0.29 \\
\pm\end{array}$ & 3 \\
\hline KYSE520 & $\begin{array}{c}0.45 \pm 0.18 \\
+++\end{array}$ & 5 & $\begin{array}{c}1.82 \pm 0.37 \\
\ldots\end{array}$ & 3 & $\begin{array}{c}0.58 \pm 0.08 \\
+++\end{array}$ & 3 & $\begin{array}{c}0.37 \pm 0.16 \\
+++\end{array}$ & 3 \\
\hline
\end{tabular}

Mean combination indices \pm sd of Gefitinib plus cytotoxic chemotherapy treatment. $\mathrm{Cl}$ recommended symbols (CalcuSyn) : antagonistic (--.); moderate antagonism (--); slight antagonism (-); nearly additive ( $t)$; moderate synergism $(++)$; synergism (+++). Number of replicate assays $=n$.

\section{Figure 3}

Dose response curves of gefitinib co-administration with cytotoxic chemotherapies. (A) Gefitinib sensitive (OE21) and gefitinib resistant (KYSE520) cells were treated with gefitinib alone, cytotoxic chemotherapy alone or equimolar titrations of both drugs (combination). Cell proliferation was determined by CellTitregloß assay, and representative graphs depict proliferation relative to solvent control treated cells (set at 100\%). (B) Table of Combination indices (CI) of gefitinib and cytotoxic chemotherapies in ESCC cell lines. Average ( \pm s.d) $\mathrm{Cl}$ values at ED75 determined by CalcuSyn software from at least three $(\mathrm{n})$ independent assays [representative dose response curves are shown in $(A)$ ]. Cl values $<1$ indicate synergistic interactions, $\mathrm{Cl}=1$ additive, $\mathrm{Cl}$ values $>1$ indicate antagonistic interactions. CalcuSyn recommended symbols are also provided to indicate the degree of the effect. 

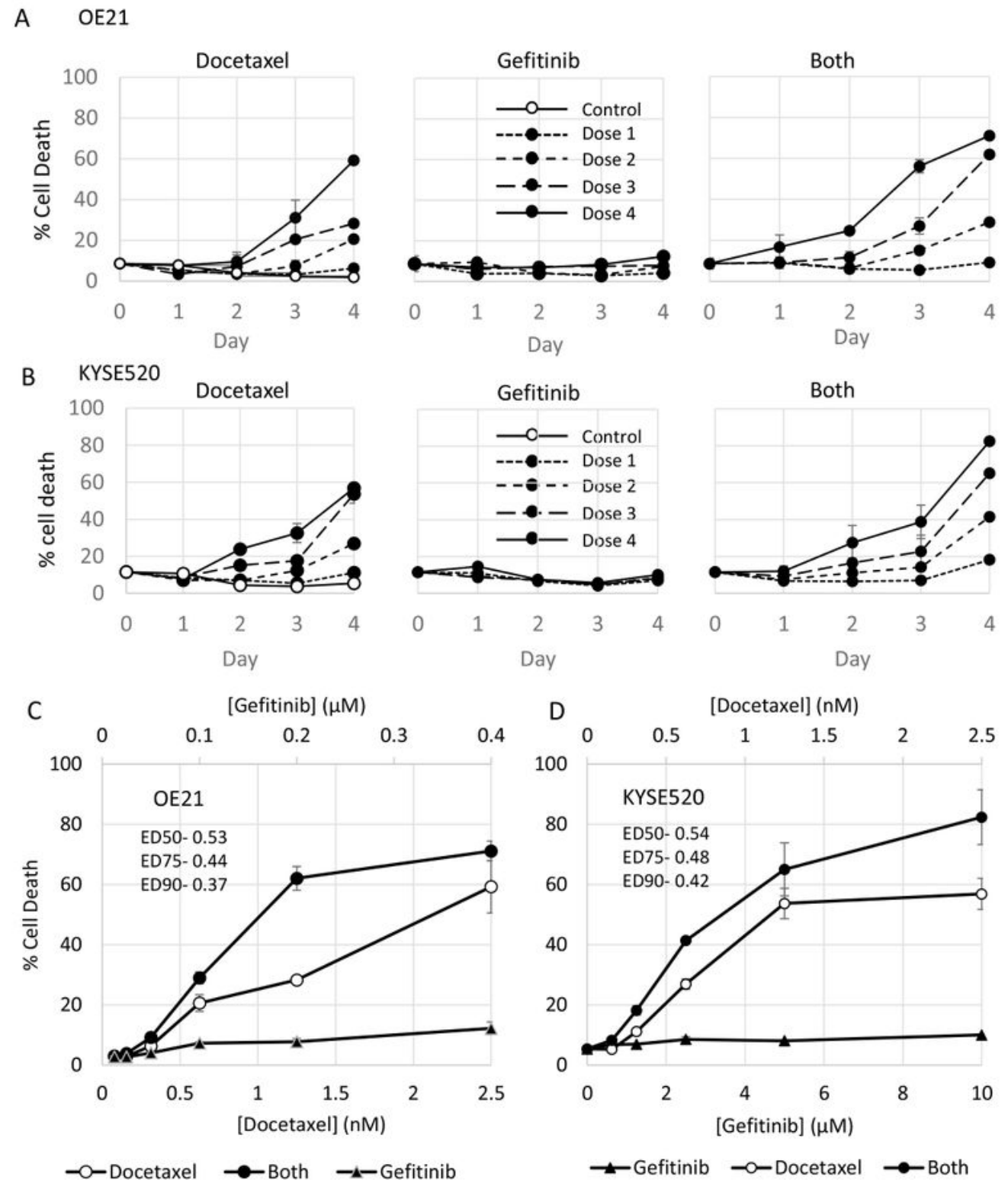

\section{Figure 4}

Docetaxel in combination with gefitinib synergistically enhances ESCC cell death. Cytotoxicity of drug treatments (docetaxel alone, gefitinib alone or gefitinib plus docetaxel combination) on the ESCC cell lines OE21 ( $A$ and $C$ ) and KYSE520 (B and D) was assessed by CellToxTM green assay and imaging (IncuCyte ${ }^{\circledR}$ Zoom). (A and B). Time course of treatment: cells were treated for four days with solvent (Control) increasing doses of docetaxel (OE21 and KYSE520: Dose $1=0.3215 n M$; Dose $2=0.625 n M$; Dose 


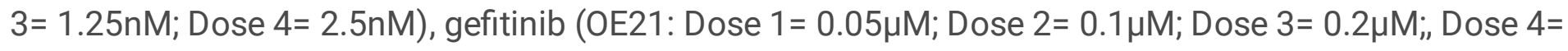
$0.4 \mu \mathrm{M}$ and KYSE520: Dose $1=1.25 \mu \mathrm{M}$; Dose $2=2.5 \mu \mathrm{M}$; Dose $3=5 \mu \mathrm{M}$; Dose $4=10 \mu \mathrm{M})$ or both drugs combined (Both). ( $C$ and D) Endpoint IncuCyte ${ }^{\circledR}$ data from Day 4 are presented as dose response curves in OE21 (C) and KYSE520 (D) (mean \pm SEM of at least three replicate wells, 4 fields per well). Synergistic combination indices at effective dose $50 \%, 75 \%$ and $90 \%$ (ED50, ED75 and ED90) are indicated.

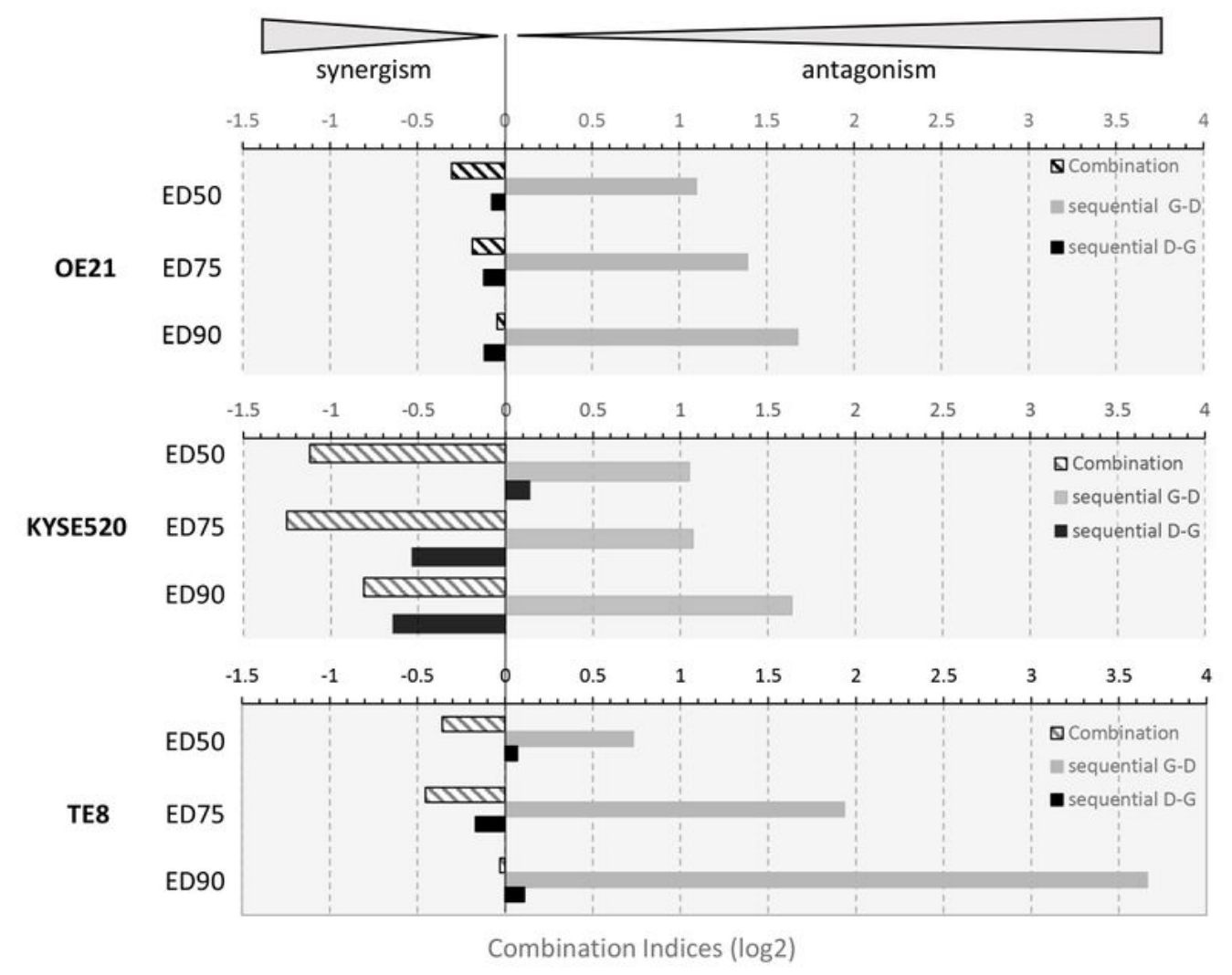

Figure 5 
Efficacy of docetaxel/gefitinib combination treatment is sequence-dependent. OE21, TE8 and KYSE520 ESCC cells were treated for four days with gefitinib and docetaxel either in combination or sequentially: four days both drugs (combination), 48 hours gefitinib treatment followed by addition of docetaxel for the remaining 48 hours ( $G-D)$ or 48 hours docetaxel treatment followed by addition of gefitinib for the remaining 48 hours $(D-G)$. Cells were analysed by CellTitre-glo $\AA$ assay and combination indices determined using CalcuSyn software. Log $2 \mathrm{Cl}$ values where $0=$ additive effects, $<0=$ synergistic effects, $>0=$ antagonistic effects at 50\%,75\% and 90\% effective dose ED50, ED75 and ED90, respectively are displayed. 